\title{
A comparison of Attitudes Toward Schizophrenia among Psychiatric Staff, Psychiatrists, Physicians, Medical Students, and Non-medical Workers
}

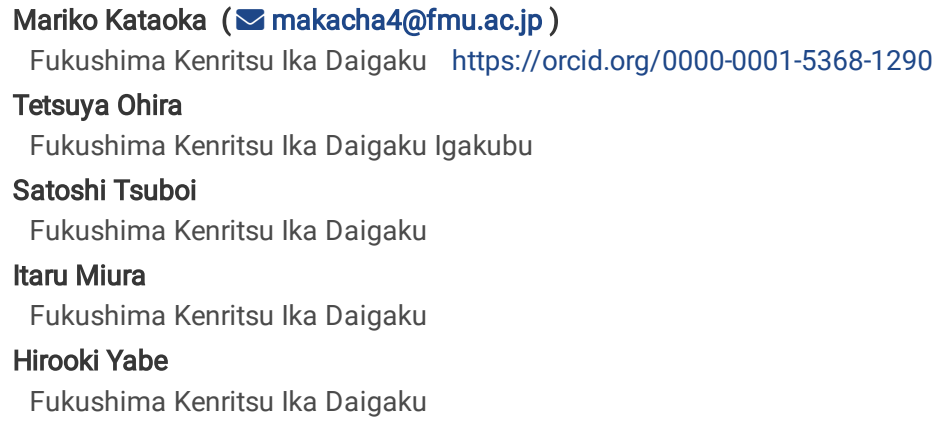




\section{Abstract}

Background: Today, schizophrenia remains stigmatized all over the world, and for patients with schizophrenia, the experience of stigma makes improving their lives difficult. Changing of attitudes toward schizophrenia is an important theme not only for medical professionals but also medical students. We therefore invested investigate negative attitudes toward schizophrenia among psychiatric staff, psychiatrists, physicians, medical students, and non-medical workers.

Methods: Participants in this study included 490 medical students, 25 psychiatric staff, 13 psychiatrists, 48 physicians, and 222 non-medical workers in Fukushima Medical University, in Japan. We conducted an internet-based questionnaire survey, using a web-based survey tool. We used an 18-item questionnaire on attitudes toward schizophrenia that comprised three factors: stigma, underestimation of patients' abilities, and skepticism regarding treatment. To compare the scores for each of these factors among the five participant groups, analysis of covariance (ANCOVA) was used to adjust for age and sex.

Results: Psychiatrists' "stigma" and "underestimation of patients' abilities" scores were significantly lower than those of non-medical workers, physicians, and medical students. The "skepticism regarding treatment" scores were not significantly different among the five groups. For medical students, hoping to become a psychiatrist in the future had the great impact on improving attitudes toward schizophrenia.

Conclusion: Medical students had more negative attitudes toward schizophrenia than psychiatrists, but equally negative attitudes compared with physicians and non-medical workers.

\section{Background}

Today, schizophrenia remains stigmatized all over the world and for patients with schizophrenia, the experience of stigma makes improving their lives [1]. The general public [2] and various professionals-such as nurses [3, 4], physicians [5], medical students [6], and even psychiatrists [7, 8]-have negative attitudes toward schizophrenia. A comparative study on attitudes toward schizophrenia in Japan [9] reported that psychiatrists had more positive attitudes toward schizophrenia than either physicians or the general population, who displayed equally stigmatizing attitudes, although the anti-stigma movement has been promoted by changing the name for schizophrenia in 2002 [10]. In an Italian study, medical students and doctors showed more stigma toward schizophreniameasured in term of assumptions that schizophrenia are dangerous and, unpredictable, and desired social distance from them-than nurses [6]. Based on these results, improving attitudes toward schizophrenia is important not only for medical professionals but also for medical students. However, it is unclear to what negative medical students have negative attitudes towards schizophrenia, and how these compare with those of non-medical workers or medical professionals.

One factor that influences medical students' attitudes toward schizophrenia is medical education [11, 12],-including psychiatric education and psychiatric training $[13,14]$-which has been shown to improve medical students' negative attitudes toward schizophrenia. On the other hand, a few studies, including a study conducted in Turkey [12], have shown that medical education has a negative influence on medical attitudes toward schizophrenia. This follow-up study conducted in Turkey [12] reported that medical students' attitudes toward schizophrenia changed significantly between their first and fifth years of medical school. It measured attitudes in terms of etiology of schizophrenia, treatment options, approach to schizophrenia patients, and social interactions. However, this study also showed that the portion of final year students who did not perceive schizophrenia as a curable disease, and those who perceived a likelihood of danger from schizophrenia patients, was higher among second year students. Thus, it is clear that psychiatric medical education can play an important role in improving medical students' attitudes toward schizophrenia, but education' specific effects on medical student are still unclear. Studies conducted in the U. K. [15] and Greece [13] suggested that personal experiences of mental health treatment, or experience with family member or friends undergoing mental health treatments are factors related to less stigmatizing attitudes toward mental illness. In addition, medical students having empathy and interesting in mental illness were likely to become psychiatrists [16]. A Japanese study reported it is possibility that medical students who hope to become psychiatrists tend to have less negative attitudes towards schizophrenia [9].

We therefore sought to investigate and compare of attitudes toward schizophrenia among non-medical workers, psychiatric staff (other than psychiatrists), physicians, psychiatrists, and medical students. We used web-based questionnaire consisting of factors extracted from multiple items in a previous study [9]. Based on the assumption that having interest in patients with mental illness would lead to less stigma influences toward schizophrenia, we hypothesized that psychiatrists and psychiatric staff would have the most positive attitudes while non-medical workers, physicians and medical students would have more negative attitudes. Further, we predicted that medical education (including psychiatric education and training), experiences of individual or a relatives' mental illness, and hope of becoming psychiatrists in the future would be factors correlated with medical students having less stigmatizing attitudes toward schizophrenia.

\section{Methods}

\subsection{Study design}

We used a web-based survey tool to conduct an internet-based questionnaire survey of individuals at Fukushima Medical University (FMU) in Japan. The study subjects were medical students in their third to sixth of medical training (third-year: $n=133$, fourth-year: $n=147$, fifth-year: $n=100$, and sixth-year: $n=$ 110), psychiatric staff $(n=25)$, psychiatrists $(n=13)$, physicians $(n=48)$, and non-medical workers (e.g., office workers in General Affairs Division, $n=222)$. In Japan, Medicine is a six year academic degree program that includes a two year pre-clinical stage followed by a four year clinical stage. Psychiatric classes that cover schizophrenia are given during fourth-year and consist of classroom lectures on the pathology, symptoms, and treatment of schizophrenia. Psychiatric training is provided in the fifth-year training and consists of clinical lessons (bed side learning; BSL) on the clinical characteristics of mental disorders and, their bio-psychosocial treatments; it also includes, tutorial clinical workshops, and attendance of clinical facilities at the Department of 
Psychiatry of the University hospital. Therefore, all fifth-year students who participated in this survey had previously completed classroom psychiatry lectures, and all sixth-year students had previously received psychiatric training. All subjects in this study were Japanese, belonged to one of the five participant groups, and had agreed to complete web-based surveys when they filled out our questionnaires on Google forms (an online questionnaire format service provided by Google). All subjects received a hyperlink to a Google forms containing various questionnaires. No identifying information (e.g., name or birth) was required of study participants. The present study was conducted from September to December 2016 and received ethical approval from the Fukushima Medical University Ethics Committee (\#2190).

\subsection{Questionnaires}

The questionnaire used in this web-based study comprised three sections: demographic information, knowledge about schizophrenia, and attitudes toward schizophrenia (measured using 18 items).

Demographic information collected from potential participants included their age, gender, number of years of education, number of years of education, number of years of psychiatric education, numbers of books read on schizophrenia, occupation/qualifications (e.g. medical students, psychiatric staff other than psychiatrists, physicians other than psychiatrists, others, etc.), annual household income (A: Less than 2 milion JPY, B: 2-3 99 milion JPY, C: 4-5 99 milion JPY, D: 6-7 99 milion JPY, E: 8-9.99 milion JPY, F:10 milion JPY and above). Medical students didn't be asked for annual household because income most of them didn't work as permanent or temporary employees. The demographic section of the questionnaire also asked if any family member or close friends had experienced ("Do you have family or close friends with a past history of psychiatric illness?"), if any family members or close friends had been diagnosed with schizophrenia ("Does that include individuals with schizophrenia?"), and whether participants had been prescribed psychiatric medications ("Have you ever been prescribed psychiatric medications, such as anxiolytics, hypnotics antidepressants, antipsychotics, and/or anticonvulsants?"). Finally, for potential medical student participants, the following additional information was collected: year of medical training at FMU, experience of taking psychiatric class of schizophrenia at FMU ("Have you ever completed psychiatry class on schizophrenia?"), BSL experience during psychiatry term at FMU ("Have you completed BSL training during your psychiatric term?"), and hope of becoming a psychiatrist ("Do you have a hope that you want to become a psychiatrist in the future?").

Participants' knowledge of schizophrenia was evaluated via three questions, each of which had five response choices (one correct and four incorrect): The first question was "Please select the approximate prevalence rate of schizophrenia", and the response choices were A: 1/50, B: 1/100 (correct answer), C: 1/300, D: 1/1000, E: 'I don't know. The second question was "What is the typical age of schizophrenia onset?", and the responses choices were A: Childhood, B: Adolescence to early adulthood (correct answer), C: Late adulthood, D: Middle age, E: 'I don't know'”. The third question was "What is the characteristic symptom of schizophrenia?", and the choices were A: Panic attack, B: Visual hallucinations, C: Auditory hallucination (correct answer), D: Obsessivecompulsive behavior, E: 'I don't know. Participants were instructed to answer these questions without referring to any materials including books.

To evaluate attitudes toward schizophrenia, we used an 18-item questionnaire developed by Hori, et al. [9]. This questionnaire was based on the 13-item questionnaire developed by Uçok A, et al. [17]. The reliability and validity of the Japanese version has been reported elsewhere [9]. We added a further, five items by referring to several prior studies on attitudes [18-21] and ended up with to the 18-item questionnaire used in the present study. The full content of the 18-item questionnaire is presented in Table 1. We asked participants to answer each question with either "I agree" or "I disagree". For items \#1, 10, 11, 12, 15, 16,17 , and 18, responses of "I agree" were scored 0 and those answered with "I disagree" were scored 1. For the other items-items number (\#2, 3, 4, 5, 6, 7, 8, 9,13 and 14), the soring was reversed. Therefore, for all items a higher score indicated a more negative attitude. The total score for each item was defined as the discrimination score. The questionnaire was composed of three factors [9]: "stigma," "underestimation of patients' abilities," and "skepticism regarding treatment." Summed scores for each factor were defined as "stigma" score, "underestimation of patients' abilities" score, and "skepticism regarding treatment" score. 
Demographic Characteristic and knowledge about schizophrenia among participants.

\begin{tabular}{|c|c|c|c|c|c|c|}
\hline characteristics & $\begin{array}{l}\text { Non-medical } \\
\text { worker }(n=93)\end{array}$ & Psychiatric staff $(n=16)$ & Physicians (n=25) & Psychiatrist (n=10) & $\begin{array}{l}\text { Medical students } \\
(n=237)\end{array}$ & $A$ \\
\hline $\begin{array}{l}\text { Gender } \\
\text { (female), \% }\end{array}$ & 55 & 63 & 12 & 20 & 39 & $x$ \\
\hline $\begin{array}{l}\text { Age } 20-29 \\
\text { years, \% }\end{array}$ & 22.3/27.7/35.1/9.6/5.3 & 25.0/31.3/31.3/12.5/0.0 & $28.0 / 40.0 / 20.0 / 8.0 / 4.0$ & $40.0 / 50.0 / 10.0 / 0.0 / 0.0$ & $98.7 / 1.3 / 0.0 / 0.0 / 0.0 / 0.0$ & $x$ \\
\hline \multicolumn{7}{|l|}{$30-39$ years, \% } \\
\hline \multicolumn{7}{|l|}{$40-49$ years, $\%$} \\
\hline \multicolumn{7}{|l|}{$50-59$ years, $\%$} \\
\hline \multicolumn{7}{|l|}{60 -years, \% } \\
\hline $\begin{array}{l}\text { Education } \\
\text { years: } \\
\text { mean } \pm S . D\end{array}$ & $15.3 \pm 2.1$ & $16.3 \pm 4.0$ & $18.4 \pm 2.1$ & $19.8 \pm 2.3$ & & $\mathbf{F}$ \\
\hline $\begin{array}{l}\text { Household } \\
\text { annual } \\
\text { income,\% }\end{array}$ & $3.0(2.0-4.0)$ & $3.0(2.0-5.0)$ & $6.0(5.0-6.0)$ & $6.0(6.0-6.0)$ & & $\begin{array}{l}k \\
\text { V }\end{array}$ \\
\hline $\begin{array}{l}\text { Experience of } \\
\text { mental illness } \\
\text { via family } \\
\text { member or } \\
\text { close friend } \\
\text { (yes), \% }\end{array}$ & 31 & 40 & 28 & 40 & 35 & $x$ \\
\hline $\begin{array}{l}\text { Experience of } \\
\text { schizophrenia } \\
\text { via family } \\
\text { member or } \\
\text { close friend } \\
\text { (yes), \% }\end{array}$ & 18 & 0 & 29 & 0 & 8 & $x$ \\
\hline $\begin{array}{l}\text { Experience of } \\
\text { being } \\
\text { prescribed } \\
\text { psychiatric } \\
\text { medications } \\
\text { (yes), \% }\end{array}$ & 29 & 27 & 44 & 40 & 8 & $x$ \\
\hline $\begin{array}{l}\text { Psychiatric } \\
\text { traing, years: } \\
\text { (25-75 } \\
\text { percentile) }\end{array}$ & $0.0(0.0-0.0)$ & $2.3(1.0-7.4)$ & $0.1(0.0-0.2)$ & $3.3(1.5-8.4)$ & & $\begin{array}{l}k \\
\text { V }\end{array}$ \\
\hline $\begin{array}{l}\text { Numbers of } \\
\text { books on } \\
\text { schizophrenia: } \\
\text { (25-75 } \\
\text { percentile) }\end{array}$ & $0.0(0.0-0.0)$ & $1.0(3.0-13)$ & $1.0(0.0-2.0)$ & $15(10-20)$ & $1.0(0.0-2.0)$ & $\begin{array}{l}k \\
\text { V }\end{array}$ \\
\hline $\begin{array}{l}\text { Knowledge } \\
\text { about } \\
\text { prevalence } \\
\text { rate of } \\
\text { schizophrenia } \\
\text { (correct), \% }\end{array}$ & 21 & 81 & 72 & 100 & 50 & $x$ \\
\hline $\begin{array}{l}\text { Knowledge } \\
\text { about onset } \\
\text { age of } \\
\text { schizophrenia } \\
\text { (correct), \% }\end{array}$ & 33 & 100 & 84 & 100 & 62 & $x$ \\
\hline $\begin{array}{l}\text { Knowledge } \\
\text { about } \\
\text { characteristic } \\
\text { symptoms of } \\
\text { schizophrenia } \\
\text { (correct), \% }\end{array}$ & 27 & 94 & 84 & 100 & 67 & $x$ \\
\hline $\begin{array}{l}\text { Numbers of } \\
\text { correct } \\
\text { answers: (25- } \\
75 \text { percentile) }\end{array}$ & $0.0(0.0-2.0)$ & $3.0(3.0-3.0)$ & $3.0(2.0-3.0)$ & $3.0(3.0-3.0)$ & $2.0(1.0-3.0)$ & $\begin{array}{l}k \\
v\end{array}$ \\
\hline
\end{tabular}

\subsection{Statistical analysis}


For continuous variables, we calculated means and standard deviations, while for ordinal variables we calculated medians (25-75 percentiles). For categorical variables, data were reported as percentages. Means, medians, and categorical variables were compared using the analysis of variance (ANOVA) or t-test, Kruskal-Willis test or Mann-Whitney $U$ test, and the $\chi 2$ test. When necessary, post-hoc pair-wise comparisons were performed to examine where exactly in the five groups the difference exacted. The ANOVA or t-test, Kruskal-Willis test, and the $\chi 2$ test were followed by the Mann-Whitney $U$ test and the pair-wise $\chi 2$ test. The means of values from each group's scores were compared using ANOVA.

Statistical significance was set at two-tailed $p<0.05$ unless otherwise specified. The conservative $p<0.05$ value was adopted to represent as statistical significance, and $p<0.1$ as signified trend-level where multiple tests were performed simultaneously. Analyses were performed using the SAS version 9.4 (SAS, Cary, North Carolina, USA).

\section{Results}

We obtained 392 responses items in this survey including invalid six responses that had no answers to the 18-item questionnaire. In addition, we considered five responses from individuals who listed their occupation as 'other' (two nurses, one public health nurse, one midwife, and one clinical laboratory technologist) as invalid. After excluding these 11 answers, we had obtained 381 valid responses from 60 third-year-students, 67 fourth-year- students, 50 fifthyear-students, 60 sixth-year-students, 16 psychiatric staff, 10 psychiatrists, 25 physicians, and 93 non-medical workers. The 16 psychiatric staff comprised 12 nurses, three clinical psychologists, and one psychiatric social worker. The valid responses rate was $45 \%$ for third-year-students, $45 \%$ for fourth-year- students, $50 \%$ for fifth-year-students, $54 \%$ for sixth-year-students, $64 \%$ for psychiatric staff, $77 \%$ for psychiatrists, $52 \%$ for physicians, and $42 \%$ for the non-medical workers. Full details of data of demographic information collected from potential participants are presented in additional file 1.

Table 1 shows participants' demographic characteristics and knowledge of schizophrenia according to the five group listed above (medical students, psychiatric staff, psychiatrists, physicians, and non-medical workers). Because basic demographic characteristics, including gender and age were significantly different among the groups, these two variables were controlled for in ANOVA model when examining the difference of attitudes.

-In the medical students group, 96 students had completed a psychiatry class on schizophrenia during their fourth-year, and 83 students had completed BSL training as part of psychiatry term during their fifth-year of the program. A further 56 students had not completed either psychiatry class on schizophrenia or BSL training. There were 36 students who had hoped to become a psychiatrist in the future, and 200 students who did not.

-Table 2 presents the results of the 18-item questionnaire on attitudes toward schizophrenia organized by participant group. It was notable that only one psychiatrist believed that schizophrenia patients are untrustworthy (item \#6), and no psychiatrist believed the following statements: schizophrenia patients are dangerous (item \#4), schizophrenia patients should be in hospitals (item \#8), patients with schizophrenia cannot comprehend their illness (item \#13), and patients with schizophrenia cannot comprehend nor apply suggested treatment (item \#14). By contrast, a substantial portion of the non-medical workers, physicians, and medical students agreed that they would not like to have a neighborhood with schizophrenia, and schizophrenia could harm children. 
Table 2

Proportions of participants who answered "I agree" to each item concerning attitudes toward schizophrenia

\begin{tabular}{|c|c|c|c|c|c|c|c|}
\hline & $\begin{array}{l}\text { Non-medical } \\
\text { worker }(n=93)\end{array}$ & $\begin{array}{l}\text { Psychiatric } \\
\text { staff }(n=16)\end{array}$ & $\begin{array}{l}\text { Physicians } \\
(n=25)\end{array}$ & $\begin{array}{l}\text { Psychiatrist } \\
(n=10)\end{array}$ & $\begin{array}{l}\text { Medical } \\
\text { students } \\
(n=237)\end{array}$ & $\begin{array}{l}\text { Analysis } \\
\chi^{2}\end{array}$ & $\mathbf{p}$ \\
\hline 1. Patients with schizophrenia can work & 73 & 100 & 92 & 100 & 78 & $x 2(4)=11.7$ & 0.0199 \\
\hline $\begin{array}{l}\text { 2. Would oppose if one of his /her relatives would } \\
\text { like to marry someone who has schizophrenia }\end{array}$ & 49 & 31 & 52 & 50 & 41 & $\chi^{2}(4)=3.53$ & 0.473 \\
\hline $\begin{array}{l}\text { 3. Schizophrenia patients can be recognized by } \\
\text { his/her appearance }\end{array}$ & 13 & 25 & 16 & 20 & 7 & $x 2(4)=9.78$ & 0.044 \\
\hline 4. Schizophrenia patients are dangerous & 28 & 13 & 24 & 0 & 30 & $\chi^{2}(4)=6.16$ & 0.187 \\
\hline $\begin{array}{l}\text { 5. Would not like to have a neighbor with } \\
\text { schizophrenia }\end{array}$ & 38 & 19 & 44 & 20 & 31 & $\chi^{2}(4)=4.85$ & 0.303 \\
\hline 6. Schizophrenia patients are untrustworthy & 40 & 19 & 24 & 10 & 28 & $\chi 2(4)=7.89$ & 0.096 \\
\hline 7. Schizophrenia patients could harm children & 57 & 38 & 56 & 20 & 59 & $x 2(4)=8.54$ & 0.074 \\
\hline 8. Schizophrenia patients should be kept in hospitals & 16 & 0 & 8 & 0 & 14 & $\chi^{2}(4)=5.50$ & 0.24 \\
\hline $\begin{array}{l}\text { 9. Family members of people with schizophrenia } \\
\text { should help with all aspects of care }\end{array}$ & 35 & 6 & 24 & 20 & 38 & $\chi 2(4)=14.5$ & 0.006 \\
\hline $\begin{array}{l}\text { 10. (Suppose you were a psychiatrist ) I don't worry } \\
\text { about examining a person who is diagnosed with } \\
\text { schizophrenia }\end{array}$ & 64 & 47 & 56 & 90 & 46 & $x 2(4)=16.2$ & 0.003 \\
\hline $\begin{array}{l}\text { 11. Would a person with schizophrenia be treated in } \\
\text { the appropriate department of the general hospital }\end{array}$ & 66 & 50 & 52 & 80 & 57 & $x 2(4)=4.50$ & 0.289 \\
\hline 12. Schizophrenia can be treated & 87 & 81 & 83 & 80 & 91 & $x 2(4)=3.43$ & 0.489 \\
\hline $\begin{array}{l}\text { 13. Patients with schizophrenia cannot comprehend } \\
\text { their illness }\end{array}$ & 28 & 13 & 28 & 0 & 28 & $\chi 2(4)=5.65$ & 0.227 \\
\hline $\begin{array}{l}\text { 14. Patients with schizophrenia cannot comprehend } \\
\text { nor apply suggested treatment }\end{array}$ & 12 & 6 & 4 & 0 & 9 & $x^{2}(4)=2.92$ & 0.571 \\
\hline 15. Schizophrenia has the chance of recovery & 95 & 100 & 88 & 100 & 96 & $\chi 2(4)=4.95$ & 0.293 \\
\hline $\begin{array}{l}\text { 16. It is important to always inform a person with } \\
\text { schizophrenia of their illness }\end{array}$ & 86 & 94 & 88 & 100 & 77 & $x 2(4)=9.16$ & 0.057 \\
\hline $\begin{array}{l}\text { 17. Patients with schizophrenia often benefit from } \\
\text { pharmacologic intervention (ie. antipsychotic } \\
\text { medications) }\end{array}$ & 86 & 100 & 100 & 100 & 91 & $x 2(4)=7.88$ & 0.096 \\
\hline $\begin{array}{l}\text { 18. Patients with schizophrenia often benefit from } \\
\text { psychotherapy }\end{array}$ & 85 & 100 & 100 & 100 & 94 & $x 2(4)=12.2$ & 0.016 \\
\hline
\end{tabular}

Figure. 1 shows the age- and sex-adjusted mean values of the five participants groups' overall discrimination scores. The overall discrimination scores were $5.0 \pm 0.36$ for non-medical workers, $3.3 \pm 0.71$ for psychiatric staff, $4.2 \pm 0.57$ for physicians, $1.8 \pm 0.87$ of psychiatrist, and $4.4 \pm 0.21$ for medical students. The adjusted overall discrimination scores for psychiatrists and psychiatric staff were significantly lower than those of non-medical workers. As shown in Figure.2, the psychiatrists and psychiatric staff groups had significantly lower adjusted mean "stigma" values than the non-medical workers group, scores were $1.2 \pm 0.24$ for psychiatrist, $1.5 \pm 0.44$ for psychiatric staff, and $2.9 \pm 0.22$ for non-medical workers. The adjusted mean value of psychiatrists' "underestimation of patients' abilities" was significantly lower than that of non-medical workers $(p=0.02)$. There were no significant differences in the adjusted values of the "skepticism regarding treatment" scores among the five groups. Furthermore, the associations were essentially unchanged after further adjustment for psychiatric medication use.

Among medical students, those who hoped to become a psychiatrist had a significantly lower age- and sex-adjusted mean "discrimination" score than students who did not want to become psychiatrists $(p=0.03)$ : the respective adjusted values were $3.3 \pm 0.41$ and $4.3 \pm 0.18$. The following characteristics were not associated with medical students' adjusted "discrimination" scores (all p>0.1): years of medical training, completion of a class on schizophrenia, BSL training during the psychiatric term, having a family member or close friend with mental illness, having a family member or close friend with schizophrenia, having been prescribed psychiatric medications, and numbers of books on schizophrenia read. Female medical students' "discrimination" scores were lower than those of male students $(p=0.08)$. The adjusted values were $3.8 \pm 0.26$ and $4.4 \pm 0.21$, respectively.

\section{Discussion}

-The main finding of this cross-sectional study is psychiatrists and psychiatric staff demonstrated less negative attitudes toward schizophrenia than nonmedical workers. This finding supports the results of previous studies. Furthermore, among medical students, those who hoped becoming a psychiatrist in the future demonstrated less negative attitudes toward schizophrenia than those who did not share this aspiration. Other factors, such as taking a psychiatry 
class on schizophrenia or completing BSL training during the psychiatric term were not associated with negative attitudes toward schizophrenia. Therefore, other modifiable factors besides hope of becoming a psychiatrist should be explored to improve medical students' attitudes toward schizophrenia.

In terms of attitudes toward schizophrenia, the result of our comparisons between the four occupational groups (non-medical workers, psychiatric staffs, physicians, psychiatrists) generally confirmed our hypothesis and supported previous findings [9]. Medical students' negative attitudes toward schizophrenia patients were similar to those of both non-medical workers and physicians, which is in line with the findings of the previous studies [6, 22]. While the previous study $[12,14]$ reported medical educational curriculum on psychiatry improved attitude of medical students towards mental illness, psychiatric education and training were not correlated with improvement to medical students' negative attitudes among the medical students in the present study. Based on this finding (and the other findings that medical students still treated schizophrenia patients with striking stigma throughout psychiatric education and training [11, 13]), tools for improving medical students' attitudes-including schizophrenia anti-stigma programs-should be established in medical schools.

Our comparisons of "stigma" and "underestimation of patients' abilities" score suggested that medical students had as much discrimination in their attitudes toward schizophrenia as non-medical workers and physicians. Given a previous study's finding that educational programs for medical students in Japan resulted in positive changes in the students' attitudes toward mental illness-specifically their attitudes toward close social distance to individuals with mental illness [23]-our "stigma" score results may indicate the necessity of anti-programs targeted at medical students. That said anti-stigma education might not be able to change attitude completely; attitudes concerning marrying an individual with schizophrenia remain highly negative. Recent studies showed that even after completing an anti-stigma program only $20 \%$ of medical students agreed with the idea that parents can let their children get married to a person with schizophrenia $[23,24]$. Moreover, given certain findings that not only medical students, but even psychiatrists are strongly opposed to the idea of their relatives marrying to a person with schizophrenia [9], educational targeted at medical students could have a limited ability to improve overall attitudes toward close social distances to individual with schizophrenia. Regarding medical students' likeness to "underestimate schizophrenia patients' abilities", according to a previous study [13], the number of medical students who underestimate of schizophrenia patients' abilities increased from $63.2 \%$ to $78.1 \%$ after psychiatric training intervention. This may be due to the effects of realistic assessment-such as medical students get shocked at first when they see a schizophrenia patient suffering from hallucination-of consequences of schizophrenia based on psychiatric training for medical students. On the other hand, our study and Hori et al.'s [9] study showed that few psychiatrists underestimate of schizophrenia patients' abilities. This suggests that professional psychiatric skills, knowledge or experiences may be linked to less negative attitudes toward schizophrenia. Further study is needed to examine this hypothesis. Specially, attitudes toward schizophrenia should be compared between medical students who are taking special psychiatric training (similar to training for psychiatrists) and those who are taking the standard program.

In terms of "skepticism regarding treatment", medical students' attitudes were similar to those of psychiatrists, and were not particularly negative. This suggests that gaining knowledge or psychiatric training are effective methods for improving medical students' attitudes toward schizophrenia [13, 25]. Our results suggest that psychiatry classes and specialized training could sufficiently improve medical students' attitudes sufficiently. Our finding that female medical students had less negative attitudes toward schizophrenia patients than their male counterparts supports the previous studies that found that women displayed less stigmatization of mental diseases than men $[15,26]$. Contrary to some previous studied $[13,15]$, in our study neither personal experience with mental illness nor having a friend or family member with mental illness influenced medical students' attitudes toward schizophrenia. This result could relate to the hypothesis [27] that high quality and high frequency contact with people with mental illness reduces stigma. Therefore, continual contact with people with schizophrenia (similar to psychiatric professionals' contact levels) would reduce stigmatization.

In addition, our study suggested that whether or not medical students hoped to become psychiatrists affected their attitudes toward schizophrenia. However, it is possible that students who hoped to become psychiatrists had less negative attitudes toward schizophrenia before they developed this aspiration. The hypothesis that hope of becoming a psychiatrist influences attitudes toward schizophrenia relates to an issue presented in Hori et al., 2011 study [9]. Hori et al. [9] found that it was unclear whether psychiatrists had the overall less negative attitudes toward schizophrenia before they became psychiatrists. Therefore, tracking changes in attitudes toward schizophrenia displayed by medical students who, during their internship and also specialized psychiatry training, hoped to become psychiatrists could reveal whether schizophrenia anti-stigma education should be introduced. If specialists who had hope of becoming psychiatrists when they were medical students have more negative attitudes toward schizophrenia, educational methods are unlikely to reduce stigma and different method would be needed. On the other hand, if specialists other than psychiatrists who decided to become psychiatrists when they were medical students have more negative attitudes toward schizophrenia, educational methods could work to reduce schizophrenia. This would, support Abdurrahman et al.'s study [24] argument that anti-stigma programs for medical students or medical interns should be offered on a regular basis.

-Our study had several limitations. First, relatively few psychiatrists were enrolled in the present study, which may have resulted in a type II error. Second, the binary-scaled format (i.e., "I agree"/ "I disagree") of the 18-item questionnaire leaves no room for "in-between" answers, and thus participants' exact attitudes may not have been captured. Finally, we collected data only in Fukushima, Japan. Thus, this study's results may differ from those studies based in other region or countries. This suggests that there is a need for larger scale studies including other medical schools in Japan or in other countries.

\section{Conclusion}

The present web-based study reported that medical students had equally negative attitudes toward schizophrenia as non-medical workers and physicians. Because current medical education including psychiatric education and training might not be associated with medical students' negative attitudes, anti-stigma interventions should be introduced at medical school. Hoping to become a psychiatrist was a factor improving medical students' attitudes toward schizophrenia. This suggests that among medical students there is a relationship between being concerned with mental illness and having less negative attitudes among.

\section{Abbreviation}




\section{Declarations}

\section{Ethics approval and consent to participate}

We considered that all of the participants had agreed to complete web-based surveys when they filled out our questionnaires on Google forms. The study was approved by the ethics committee of Fukushima medical university, Fukushima, Japan.

\section{Consent for publication}

Not applicable.

\section{Availability of data and materials}

All data generated or analysed during this study are included in this published articles' supplementary information files.

\section{Competing interests}

The authors have no competing interests.

\section{Funding}

Not applicable.

\section{Author contribution}

MK and TO conducted study design, literature search, data analysis, data interpretation, and drafting of manuscript.

ST participated in the analysis and interpretation of the data.

IM and HY participated in the discussion and corrections of the manuscript.

All authors were involved in the critical revision of drafts and approved the final manuscript version.

\section{Acknowledgments}

We are grateful to Dr. Hori Hiroaki for his approval of the Japanese version of the questionnaire. We are also thankful to all participants from Fukushima Medical University.

\section{Reference}

1. Thomicroft G, Brohan E, Rose D, Sartorius N, Leese M; INDIGO Study Group. Global pattern of experienced and anticipated discrimination against people with schizophrenia: a cross-sectional survey. Lancet 2009;373(9661):408-15.

2. González-Torres MA, Oraa R, Arístegui M, Fernández-Rivas A, Guimon J. Stigma and discrimination towards people with schizophrenia and their family members. A qualitative study with focus groups. Social Psychiatry Psychiatric Epidemiology 2007;42(1):14-23.

3. Kukulu K, Ergün G. Stigmatization by nurses against schizophrenia in Turkey: a questionnaire survey. Journal Psychiatric Mental Health Nursing 2007;14(3):302-9.

4. Ross CA, Goldner EM. Stigma, negative attitudes and discrimination towards mental illness within the nursing profession: a review of the literature. Journal Psychiatric Mental Health Nursing 2009;16(6):558-67.

5. Nazan A, Yigit A, Inandi T, Kirpinar I. Attitudes of Hospital Staff Toward Mentally III Patients in a Teaching Hospital, Turkey. International Journal Social Psychiatry 2003;49(1):17-26.

6. Serafini G, Pompili M, Haghighat R, Pucci D, Pastina M, Lester D, Angeletti G, Tatarelli R, Girardi P. Stigmatization of schizophrenia as perceived by nurses, medical doctors, medical students and patients. Journal Psychiatric Mental Health Nursing 2011;18(7):576-85.

7. Uçok A, Polat A, Sartorius N, Erkoc S, Atakli C. Attitudes of psychiatrists toward patients with schizophrenia. Psychiatry Clinical Neuroscience 2004;58(1):89-9.

8. Carlos N, Rössler W, Lauber C. Attitudes of Mental Health Professionals Toward People with Schizophrenia and Major Depression. Schizophrenia Bull 2006;32(4):709-14. 
9. Hori H, Richards M, Kawamoto Y, Kunugi H. Attitudes toward schizophrenia in the general population, psychiatric staff, physicians, and psychiatrists: a web-based survey in Japan: Psychiatry Research 2011;186(2-3):183-9.

10. Sartorius N, Chiu H, Heok KE et al. Name change for schizophrenia. Schizophrenia Bull 2014;40:255-255.

11. Ay P, Save D, Fidanoglu O. Does stigma concerning mental disorders differ through medical education? A survey among medical students in Istanbul. Social Psychiatry Psychiatric Epidemiology 2006;41(1):63-7.

12. Aysen E, Kuzeymen B, Orken A, Cengiz C, A.Burak U. The medical education on attitudes toward schizophrenia; A five year follow-up study. Turkish Journal of Psychiatry 2016;27(3):176-184.

13. Marina E, Lily E. P, Eleni L, Costas N. S. Medical students' belief and attitudes towards schizophrenia before and after undergraduate psychiatric training in Greece. Psychiatry Clinical Neuroscience 2012;66(1):17-25.

14. Tarun Y, Kishore A, Dinesh K, Yatan Pal SB. Impact of psychiatric education and training on attitude of medical students towards mentally ill: a comparative analysis. Industrial Psychiatry Journal 2012;1(1): 22-31.

15. Korszun A, Dinos S, Ahmed K, Bhui K. Medical student attitudes about mental illness: does medical-school education reduce stigma? Academic psychiatry 2012;36(3):197-204.

16. Melissa D, Femi O, Jayne G. Reasons for choosing to specialize in psychiatry: differences between core psychiatry trainees and consultant psychiatrists. BJPsych Bulletin 2016;40(1):19-23.

17. Uçok A, Soygür H, Atakli C, Kuşcu K, Sartorius N, Duman ZC, Polat A, Erkoç S. The impact of antistigma education on the attitudes of general practitioners regarding schizophrenia. Psychiatry Clinical Neuroscience 2006;60(4):439-43.

18. Ruhnke GW, Wilson SR, Akamatsu T, Kinoue T, Takashima Y, Goldstein MK, Koenig BA, Hornberger JC, Raffin TA. Ethical decision making and patient autonomy: a comparison of physicians and patients in Japan and the United States. Chest 2000;118(4):1172-82.

19. Hübner-Liebermann B, Spiessl H, Iwai K, Cording C. Treatment of schizophrenia: implications derived from an intercultural hospital comparison between Germany and Japan. The International Journal of Social Psychiatry 2005;51(1):83-96.

20. Schulze B. Stigma and mental health professionals: a review of the evidence on an intricate relationship. International Review Psychiatry 2007;19(2):137-55.

21. Kuroda N, Sun S, Lin CK, Morita N, Kashiwase H, Yang F, Nakatani Y. Attitudes toward taking medication among outpatients with schizophrenia: crossnational comparison between Tokyo and Beijing. Environmental Health Preventive Medicine 2008;13(5):288-95.

22. Farooq Naeem, Ayub M, Javed Z, Irfan M, Haral F, Kingdon D. Stigma and psychiatric illness. A survey of attitudes of medical students and doctors in Lahore, Pakistan. Journal of Ayub Medical College Abbottabad 2006;18(3):46-9.

23. Mino Y, Yasuda N, Tsuda T, Shimodera S. Effects of a one-hour educational program on medical students' attitudes to mental illness. Psychiatry Clinical Neuroscience 2001;55(5):501-7.

24. Abdurrahman A, Medaim Y, Alp Ucok, Koksal A, Mustafa O. Effects of an antistigma program o medical students' attitudes towards people with schizophrenia. Psychiatry and Clinical neuroscience 2006;60:283-288.

25. David L. P, Kim G, B. A.,Tamara D, William D. S, Calvin P. G, Mary S. Dispelling the Stigma of Schizophrenia: What Sort of Information Is Best? Schizophrenia Bulletin 1994;20(3):567-578.

26. Janoušková M, Weissová A, Formánek T, Pasz J, Bankovská Motlová L. Mental illness stigma among medical students and teachers International Journal Social Psychiatry 2017;63(8):744-751.

27. Ando S, Yamaguchi S, Aoki Y, Thornicroft G. Review of mental-health-related stigma in Japan. Psychiatry Clinical Neuroscience 2013;67(7): 471-82.

\section{Figures}




\section{Discrimination}

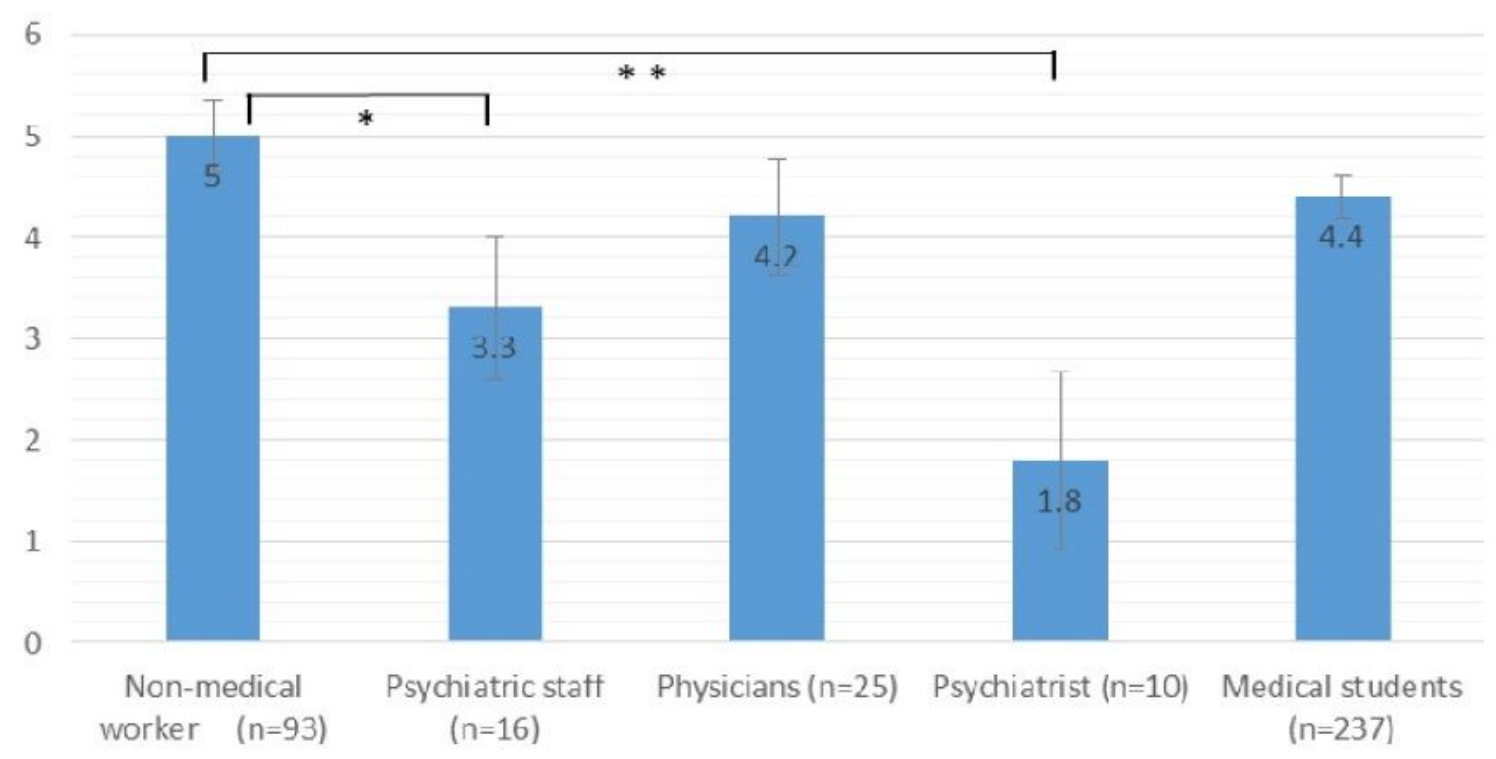

Fig.1 Age- and sex-adjusted mean values of participants "discrimination" scores

$\left(\mathrm{p}^{* * *}<0.01,0.05<\mathrm{p} *<0.10\right)$

Figure 1

Age- and sex-adjusted mean values of participants "discrimination" scores 


\section{Stigma}

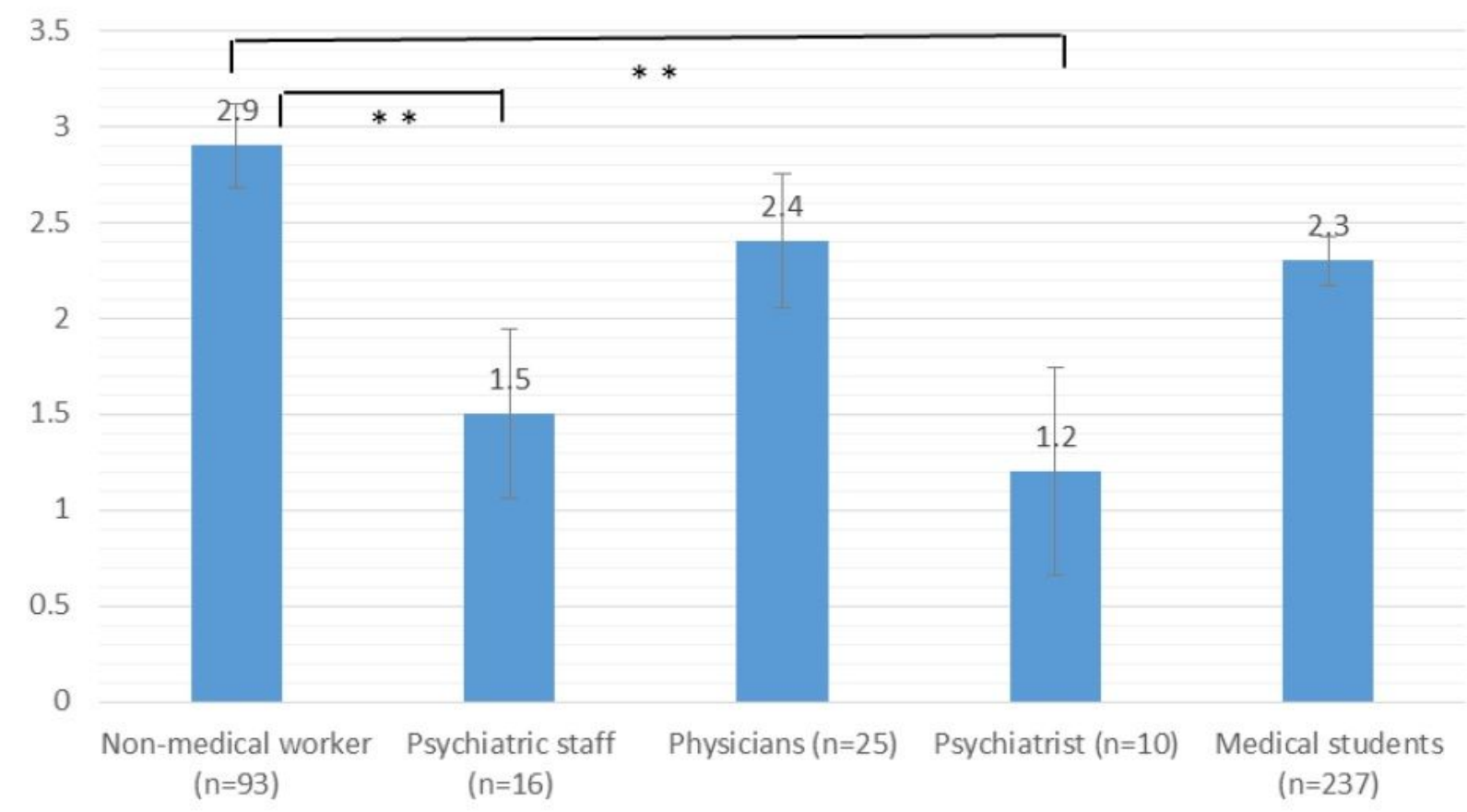

Fig.2 Age- and sex-adjusted mean values of participants "stigma" scores $\left(\mathrm{p}^{* * *}<0.01\right)$.

Figure 2

Age- and sex-adjusted mean values of participants "stigma" scores

\section{Supplementary Files}

This is a list of supplementary files associated with this preprint. Click to download.

- BMCpsychiatryrawdata.xlsx 